\section{Drugs and cardiovascular risk in inflammatory arthritis: another case of glucocorticoid-bashing?}

I read with interest the meta-analysis by Roubille et al, ${ }^{1}$ especially for the adverse effects noted with glucocorticoids (GCs). The data appear to confirm the risk of GC, which is surprising in view of the stated objective to include evidence from clinical trials. In a recent meta-analysis of randomised controlled trials (RCTs) that I participated in, no increased cardiovascular risk was found in 66 comparisons and a total of 4831 patients. $^{2}$

However, the explanation is quickly found on careful inspection of the methods: the authors chose to exclude all studies reporting on $<400$ patients. No reason is given for this decision, but the result is to effectively exclude all RCTs of GC, as these are investigator-initiated trials that do not reach this size. This is confirmed in their figure $2 \mathrm{D}$, which lists only observational studies on GC risk.

There are good reasons not to rely solely on RCTs for a good estimate of safety issues (relatively short exposure, selected population, low sample size), but there is no good reason to exclude these studies from a meta-analysis simply because they are perceived to be not large enough.

There are even better reasons not to rely solely on observational studies to get a good estimate of safety issues related to GC. Most, if not all, of such studies suffer from confounding by indication: patients with more severe and therapy-resistant rheumatoid arthritis and more comorbidities are more likely to be treated with GC, and thus more likely to experience adverse events which are then attributed to GC. Such confounding cannot be repaired by statistical adjustment techniques. ${ }^{3}$

In all, this review unfortunately recycles flawed observational data, ignores data from RCTs and thus beats on the same old tired drum to bash GC. It does not help to answer the important unanswered questions on the real balance of benefit and harm, and the place of GC in our therapeutic armamentarium.
Given the problems noted above, answers to these questions will have to come from pragmatic trials of sufficient size and duration.

\section{Maarten Boers}

Correspondence to Dr Maarten Boers, Department of Epidemiology and Biostatistics; Amsterdam Rheumatology and Immunology Center, VUmc, Amsterdam 1007 MB, The Netherlands; eb@vumc.nl

Competing interests None.

Provenance and peer review Not commissioned; internally peer reviewed.

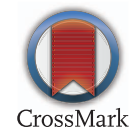

To cite Boers M. Ann Rheum Dis 2015;74:e33.

Received 5 February 2015

Accepted 6 February 2015

Published Online First 24 February 2015

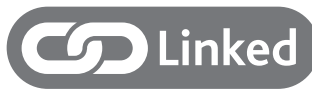

http://dx.doi.org/10.1136/annrheumdis-2015-207419

Ann Rheum Dis 2015;74:e33. doi:10.1136/annrheumdis-2015-207412

\section{REFERENCES}

1 Roubille C, Richer V, Stamino T, et al. The effects of tumour necrosis factor inhibitors, methotrexate, non-steroidal anti-inflammatory drugs and corticosteroids on cardiovascular events in rheumatoid arthritis, psoriasis and psoriatic arthritis: a systematic review and meta-analysis. Ann Rheum Dis 2015;74:480-9.

2 Tarp S, Bartels EM, Kirwan JR, et al. Adverse effects of glucocorticoid therapy in rheumatoid arthritis: a systematic review and meta-analysis of randomized controlled trials. Ann Rheum Dis 2012;71(Suppl 3):207.

3 Boers M. Studying the benefit/risk ratio of glucocorticoids in rheumatoid arthritis. J Rheumatol 2007;34:661-3. 